\title{
OS ETHÉS DA MÃE DAS GÊMEAS FARIDA E CAROLINDA EM TERRA SONÂMBULA, DE MIA COUTO
}

\author{
THE ETHÉS FROM THE MOTHER OF TWINS \\ FARIDA AND CAROLINDA FROM MIA COUTOS'S \\ SLEEPWALKING LAND
}

Shirley Maria de Jesus"

Resumo: Este artigo, a partir da noção de ethos, revisitada por Maingueneau, principalmente, na sua obra Ethos discursivo, pretende verificar como se constrói os ethé "pré-discursivo", "discursivo mostrado" e "discursivo dito" da matriarca das gêmeas Farida e Carolinda, no romance Terra sonâmbula, de Mia Couto. A partir desse referencial teórico, realizamos, ao mesmo tempo, uma análise qualitativa, linguísticodiscursiva e interdisciplinar dos ethé presentes no discurso dessa mãe. Trata-se, portanto, de uma pesquisa metodológica teórica, que se alicerça nas interfaces entre a Linguística, mais especificamente a Análise do Discurso, o ethos no discurso literário e a História. Como resultado, temos que a representação dos ethé ("pré-discursivo", "discursivo mostrado" e "discursivo dito") e a "identificação" da personagem do romance contribuem para a construção dos processos de negociação de sentidos e para a percepção dos "imaginários sociodiscursivos" individuais, coletivos e, ao mesmo tempo, de Moçambique.

Palavras-chave: Ethos. Terra sonâmbula. Maingueneau.

Aвstract: This article aims at verifying the construction of the "pre-discursive", the "said" and the "shown discursive" ethé in Mia Couto's Sleepwalking Land of the character presented in the narrative as mother of the twins Farida and Carolinda taking into consideration the notion of ethos by Maingueneau, mainly in his work Ethos Discursivo (Discursive Ethos). From this theoretical framework, qualitative, linguistic-discoursive and interdisciplinary analyses of the ethé in the mother discourse were conducted. Hence, this methodologic-theoretical research is based on the interface between Linguistics, more specifically Discourse Analysis, and ethos in the literary discourse and History. It was possible to conclude that the ethé representation and the character "identification" contribute to the senses negotiation processes making and to the perception of individual, collective and Mozambique's "sociodiscoursive imagination".

KerworDs: Ethos. Sleepwalking land. Maingueneau.

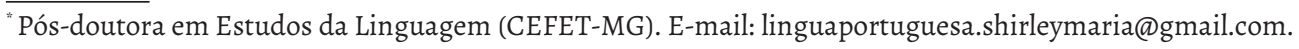




\section{CONSIDERAÇõES INICIAIS}

Noções advindas da Retórica vêm sendo muito exploradas no campo da Análise do Discurso (AD). As noções de ethos e de pathos, especialmente, são incorporadas às diversas versões da AD, principalmente, por Amossy (2005), Charaudeau (2011) e Maingueneau (2011, 2008a, 2008b, 2006, 2005, 2001), que celebrou os 10 anos da publicação do seu livro Ethos discursivo (2008b) e, por isso, este artigo trata das subcategorias de ethos abordadas por Maingueneau na referida obra e como podemos utilizá-las para analisar o discurso literário de uma das personagens mulheres no romance Terra Sonâmbula, de Mia Couto (1995), identificada na narrativa como mãe das gêmeas Farida e Carolinda.

Quanto ao ethos, além de a noção clássica ter sido resgatada, também o foi a discussão clássica sobre o entendimento dessa noção e, por isso, são comuns, hoje, as expressões 'ethos construído' e 'pré-construído' (CHARAUDEAU, 2011); 'ethos discursivo' e 'ethos prévio' (AMOSSY, 2005); 'ethos pré-discursivo', 'discursivo mostrado' e 'discursivo dito' (MAINGUENEAU, 2008b). Assim sendo, contemplando mais detalhadamente os estudos de Maingueneau, pretendemos demonstrar como esse analista do discurso busca adaptar o conceito de ethos retórico às suas teorias, relacionando-o, inclusive, a outros conceitos. $\mathrm{Na}$ sequência, apresentamos a análise dos ethé da personagem selecionada em Terra Sonâmbula (COUTO, 1995), a fim de demonstrar como essa categoria - ethos - pode ser, inclusive, utilizada na análise do discurso literário.

\section{O ETHOS NA CONCEPÇÃo de MaINGUENEAU}

Maingueneau (2008a), para tratar da noção de ethos, traz à tona elementos que, segundo ele, devem fazer parte de sua composição, tais como: cena enunciativa, fiador, corporalidade, incorporação e tom. Esses conceitos serão tratados de forma sucinta para nos dedicarmos a essa noção e suas subcategorias, a saber: 'ethos pré-discursivo', 'discursivo mostrado' e 'discursivo dito'.

De acordo com Maingueneau (2008a, p. 55-56), o ethos foi explorado na França, nos anos 1980, por alguns estudiosos, sendo um deles, Ducrot que "[...] integra ao ethos uma conceituação enunciativa [...]" e, na sequência, pelo próprio pesquisador que se propõe a trabalhar de forma a integrar ao conceito de ethos dimensões do discurso, designando entre elas um lugar determinante para a enunciação e para o locutor. Maingueneau (2008b) é considerado, também, um dos primeiros a apontar a vocação interdisciplinar da categoria de ethos.

Para o estudioso (2008b), o ethos constrói-se por meio do discurso que demanda a interação entre locutor e destinatário. Essa interação permite ao primeiro provocar determinados efeitos em seu destinatário, possibilitando a esse descortinar o ethos daquele. Na concepção de 
Maingueneau (2008b), nessa situação de comunicação, o ethos articula o verbal e o não verbal a partir de determinada conjuntura sociohistórica que abrange um habitus - "[...] princípios geradores e organizadores de práticas e de representações [...]" sociais os quais os faz passar por corretos ou, pelo menos, adequados à situação de comunicação. (BOURDIEU, 1980, citado por MAINGUENEAU, 2001, p. 147) Assim sendo, o ethos dos sujeitos (locutor e destinatário) vincula-se ao processo de comunicação. E ao interpretar seu papel durante a enunciação, o locutor torna-se, fiador, concepção encarnada do ethos (MAINGUENEAU, 2006, p. 271), de seu discurso, pois incorpora, em seu ethos, propriedades, tais como representações sociais aceitas, validadas pelos destinatários, proporcionando uma identidade que, supostamente, deve fazer surgir com sua enunciação. Em suas palavras,

[...] a questão do ethos está ligada à da construção da identidade. Cada tomada da palavra implica, ao mesmo tempo, levar em conta representações que os parceiros fazem um do outro e a estratégia de fala de um locutor que orienta o discurso, de forma a sugerir através dele certa identidade. (MAINGUENEAU, 2008a, p. 59-60)

O conceito de ethos, portanto, está ligado à construção da identidade, porque todo discurso, ao ser elaborado, o faz com base nas representações sociais que orientam locutor e destinatário. E como o ethos constrói-se na interlocução, parece-nos pertinente nos apropriarmos da nomenclatura de Hall (1999), identificação, pois, assim como o ethos, ela, a todo momento, está sob a influência de diversos fatores, cambiando, adequando-se, reestruturando-se a partir da situação de comunicação, do tempo, dos imaginários, do contexto social e histórico, da memória, da cultura, entre outros fatores.

O pesquisador (2008a, p. 60), ao tentar integrar as dimensões do discurso ao conceito de ethos, explicita que esse pode assumir um caráter pré-discursivo. O que implica que o destinatário vai construindo previamente representações sociodiscursivas do locutor a partir do que se sabe ou se acredita saber sobre esse locutor, assim como, das representações que circulam na sociedade. Ainda de acordo com Maingueneau (2006, p. 269), mesmo que o destinatário desconheça quaisquer informações sobre o locutor, pelo fato de um texto pertencer, por exemplo, a determinado gênero de discurso ou a um posicionamento ideológico, isso já pode levá-lo a atribuir àquele um determinado ethos. Dessa maneira, mesmo sendo o ethos 'pré-discursivo' construído, primordialmente, pelo destinatário, podemos notar que tanto ele quanto o locutor podem desmenti-lo, corroborá-lo, retificá-lo, entre outras possibilidades.

Aplicando a noção de ethos 'pré-discursivo' ao nosso corpus, Terra sonâmbula (COUTO, 1995), notamos que sua inscrição no gênero literário e no gênero romance, bem como o conhecimento de informações biográficas sobre o autor podem condicionar nossa leitura e induzir nossas expectativas na construção dos ethé 'pré-discursivos' das personagens e, inclusive, do autor. 
Por outro lado, Maingueneau (2008a, p. 63), ao se debruçar sobre o 'ethos discursivo' (dito e mostrado), afirma que esse ethos é de responsabilidade do locutor, constituindo-se na sua materialidade, no presente discursivo e, ao mesmo tempo, na atualização do ethos 'pré-discursivo' durante a enunciação. O ethos 'discursivo mostrado', segundo o pesquisador (2008b), deve ser percebido sem ser necessariamente mostrado. Ele é construído extradiscursivamente nas escolhas efetuadas pelo locutor e por meio das inferências realizadas pelo destinatário na própria enunciação - o que nos mostra que nele deve haver correspondência entre o discurso que o texto (falado ou escrito) traz e a interpretação realizada pelo destinatário. O analista do discurso (2008b) caracteriza, ainda, o ethos 'dito' como o próprio discurso do locutor, ou seja, relacionado ao enunciado, ao conteúdo, ao significado e que oferece ao destinatário informações de ordem social (logos) ou psicológica (pathos) sobre si mesmo e que contribuem para a construção de seu ethos.

Esse pesquisador (2008b) propõe, portanto, um ethos discursivo, já que se constrói no e pelo discurso, ligado ao plano da expressão, cujo tom - expresso por uma voz que atesta o que é dito - e cuja corporalidade se mesclam. Maingueneau (2008b, p. 18) declara que ao optar pelo termo tom, opta por uma "[...] concepção "encarnada" do ethos [...]. Esse ethos recobre não só a dimensão verbal, mas também as características, o conjunto de determinações físicas e psíquicas ligados ao fiador pelas representações coletivas estereotípicas." Ainda segundo o analista do discurso (2008b), ele prefere o termo tom por remeter tanto à escrita quanto à fala. Já a concepção do conceito de corporalidade permite-nos compreender a escrita como um corpo que ocupa um espaço que é construído e reconstruído pelo locutor para ocupar determinado espaço social, permitindo-lhe conferir a si e ao seu destinatário uma posição institucional (credibilidade diante do lugar que o locutor ocupa no momento da enunciação e que marca sua relação com um saber e, portanto, legitima seu discurso), uma vez que o lugar de onde fala também significa - característica reafirmada, inclusive, por Amossy (2005). E é esse lugar ou posição que vai delineando também o ethos coletivo da sociedade da qual a personagem mulher (a mãe das gêmeas Farida e Carolinda), na obra selecionada para este estudo, faz parte ou diz fazer, já que trabalhamos com obra de estatuto ficcional, mas que também traz em si aspectos do real e do imaginário moçambicano.

Dessa maneira, o "[...] ethos implica, com efeito, uma disciplina do corpo apreendido por intermédio de um comportamento social." (MAINGUENEAU, 2011, p. 98) Em outras palavras, o locutor não se deixa notar apenas como um estatuto; ele se articula como uma voz que se associa à representação de um corpo enunciante (fiador) em uma determinada cena de enunciação, com determinado tom, em determinado tempo, espaço, situação de comunicação e gênero discursivo. O ethos, portanto, depende dessas categorias e, por isso, pode assumir identificações diferentes a cada enunciação.

Diante do exposto, Maingueneau (2006) afirma-nos que, durante a enunciação, locutor e destinatário reivindicam uma face, uma imagem, constituída a partir de determinados 
atributos sociais compartilhados por todos em uma mesma comunidade. A face, enquanto persona, busca identificar-se com esse discurso investido de valores socialmente definidos. O enunciador, como ser empírico, no espaço em que se situa ao ocupar determinado lugar ou posição, pode delinear, portanto, um ethos - que se apresenta como uma de suas faces que se constrói na/pela representação das várias imagens que o ethos carrega e acumula em si nos mais variados gêneros discursivos, inclusive, o literário. E essas imagens, por sua vez, constroem sua identificação pela enunciação de maneira encarnada - discurso enquanto um corpo, consoante Maingueneau (2008b).

E é a partir dessas considerações que confirmamos que Maingueneau (2006) considera o ethos uma noção sociodiscursiva, já que se constrói no e pelo discurso interligado a uma dada conjuntura sociohistórica. Em outros termos, Maingueneau (2006) mostra-nos que um locutor, como um corpo de uma comunidade, para se comunicar com as pessoas que a habitam, deve construir seu discurso a partir dos valores e dos imaginários que permeiam essa sociedade; deve parecer ser um de seus membros, conhecedor de seus costumes.

Diante dessas considerações, Maingueneau demonstra-nos que o ethos, na Análise do Discurso, não deve ser entendido somente como uma categoria que se vale das provas retóricas ethos, pathos e logos para persuadir o auditório, conforme recomendava Aristóteles (384-322 a.C., 1988). Desse modo, para Maingueneau (2008a, p. 69-70),

Em uma perspectiva do discurso, não podemos nos contentar, como na retórica tradicional, em fazer do ethos um meio de persuasão: ele é parte pregnante da cena de enunciação, com o mesmo estatuto que o vocabulário ou os modos de difusão que o enunciado implica por seu modo de existência. O discurso não resulta da associação contingente de um "fundo" e de uma "forma"; não se pode dissociar a organização de seus conteúdos e do modo de legitimação de sua cena de fala.

De acordo com o pesquisador (2008a), o conceito de ethos, constituinte das cenas de enunciação, assume, na Análise do Discurso, caráter analítico-descritivo, distanciando-o, portanto, do caráter estratégico e normativo, enquanto arte de persuasão, difundido pela teoria das provas retóricas de Aristóteles (384-322 a.C., 1988). Ainda segundo o analista do discurso (2008a), o fato de o destinatário ter papel ativo na construção do ethos do locutor demonstra que o ethos é efeito do discurso, levando-se em consideração que há vários elementos ocasionais no processo de comunicação - características psíquicas e físicas reveladas pelo locutor e do tom, na qualidade de dimensão vocal desvelada pelo discurso - em relação aos quais é difícil dizer se fazem ou não parte do discurso, mas que influenciam na construção do ethos, tanto pelo locutor quanto pelo destinatário. Dessa maneira, a perspectiva que o estudioso adota ultrapassa o domínio da argumentação e mostra-nos que o ethos não se manifesta somente como um papel e um estatuto; ele se deixa apreender também como uma voz e um corpo. 
Na sequência, veremos como podemos nos valer das subcategorias de ethos de Maingueneau ('ethos pré-discursivo', 'discursivo mostrado' e 'discursivo dito') para analisar os ethé de uma personagem ficcional no discurso literário.

\section{Os ethé da mãe das gêmeas Farida e Carolinda, no romance Terra sonâmbula, DE Mia Couto}

Nossa personagem analisada é mãe das gêmeas Farida e Carolinda (COUTO,1995). No Quarto caderno de kindzu (A filha do céu), descobrimos que Farida é "filha do céu", por sua condição de gêmea. Na vila em que habitam, isso implica futuras tragédias para os habitantes e, para evitá-las, uma criança deveria ser escolhida para a vida; e outra, para a morte. Caso contrário, as chuvas jamais voltariam a cair na comunidade, levando à inexistência das plantações, à falta de água para o gado e assim por diante. Segundo Chevalier e Gheerbrant (1991, p. 465),

Os gêmeos simbolizam, por outro lado, o estado de ambivalência do universo mítico. Aos olhos dos primitivos, aparecem sempre carregados de uma força poderosa, seja perigosa e protetora, seja apenas perigosa ou apenas protetora... Temidos e venerados, os gêmeos se apresentam sempre carregados de um valor intenso.

Ou, ainda, consoante Leite (2013, p. 51),

Grande parte das histórias relatadas em Terra sonâmbula fundamentam-se em crenças dos Tsonga do sul de Moçambique e na sua mundividência. [...] E passo a citar Henri Junod: "Esta potência que causa o relâmpago e a morte está ligada também de maneira muito especial ao nascimento dos gémeos, de modo que a mãe deles é chamada Tilo, o Céu, e crianças, Baana bá Tilo, Filhos do céu". (1974, p. 396) O nascimento de gémeos é considerado uma desgraça, e implicava antigamente a morte de um, e a execução de ritos de purificação para a mãe e para a criança que sobrevivia, sempre marginalizada pela comunidade. (Conforme o original)

Esse ritual, obviamente, remete-nos a um dos imaginários sociodiscursivos dessa vila. Há que se notar, ainda, que a simbologia dos gêmeos, ou melhor, que esse ethos 'pré-discursivo' (MAINGUENEAU, 2008b) mostra-nos o porquê de as mulheres locais, responsáveis por determinados rituais, realizarem cerimônias para evitar a seca: uma das gêmeas, no caso, Carolinda, deve ser submetida à fome, até sua morte, para ser enterrada no "[...] bosque sagrado onde dormem as crianças falecidas [...]”. (COUTO, 1995, p. 85) Nesse ritual, estabelece-se, ainda, que a mãe não pranteie a suposta morte da filha - que, na verdade, foi levada embora por um casal. Após a cerimônia, mãe e filha (Farida) são banidas para longe da vila, por serem impuras - o que implica que o 'ethos mostrado' (MAINGUENEAU, 2008b) e esse estereótipo 
de ambas (conforme termo de AMOSSY, 2005), no caso, negativo, revelam que os estereótipos também produzem discriminações dentro do grupo social, ou seja, identificações sociais negativas. Esse primeiro episódio revela-nos que o ethos local vale-se de tradições rigorosas para o estabelecimento de certo equilíbrio de seu meio ambiente, e que os rituais são traços desse ethos que sinalizam a importância da mulher em sua sociedade, já que somente elas podem executá-los. A mulher, portanto, tem ligação, ou melhor, identificação com a natureza dentro de sua sociedade, assim como, com as tradições locais. E isso reafirma-nos um dos imaginários sociodiscursivos da nação moçambicana, sobretudo, da sociedade rural.

Como dito, a mãe das gêmeas, tal qual a mãe de Kindzu (outra personagem do romance aqui em análise), é apresentada, na narrativa, por sua posição ou status - mãe. O que nos permite inferir que atribuir um nome próprio pode funcionar como espécie de artifício que faz prevalecer a identidade sobre a diferença e que a falta de nomeação pretende, nesse caso, demonstrar que, mesmo durante os períodos de guerras (no caso de Moçambique, guerra de independência de Portugal e guerra civil), matriarcas e idosos tendem a manter seu status, sua identidade como aqueles que transmitem e mantêm as tradições, conforme notamos na narrativa de Couto (1995). Esse status é mantido desde que eles possam desempenhar suas funções de acordo com o ethos local. Como vimos, embora ela, como mãe de filhos gêmeos, seja excluída do convívio da comunidade, deve continuar executando os rituais sempre que necessário.

A progenitora das gêmeas deixa entrever, na narrativa, que não observa, completamente, as tradições de sua comunidade. Ela nega-se a cumprir parte da tradição, poupando a vida da filha Carolinda, deixando-nos notar que seu pathos entra em conflito com o ethos coletivo, dando vasão a um logos que parece questionar uma tradição tão severa, em um tempo em que os bandos armados já efetuam tantas mortes. Isso sinaliza para a rasura do ethos coletivo em tempos de guerra e para o fato de que determinados estereótipos não estão imunes a mudanças.

Em relação a essa mãe, não temos seu ethos 'discursivo' durante o suposto período de luto pela morte de Carolinda, mas temos seu ethos 'pré-discursivo' fundado no ethos coletivo. Se a mãe é também responsável por transmitir os conhecimentos culturais e ancestrais, conforme se nota na narrativa, seu ethos 'pré-discursivo' mostra-nos, portanto, que ela deve ensinar a Farida que a morte de Carolinda foi um gesto de bondade para "aliviar a maldição" de acordo o ritual (chimussi) praticado por milênios. Assim, temos mais um elemento da visão de mundo dessa comunidade. (COUTO, 1995, p. 85) Entretanto, quando essa mãe é convocada para nova cerimônia, sendo enterrada no lodo, local onde supostamente também estava enterrada Carolinda, e solicita: "[...] me deixem, tenho frio" (COUTO, 1995, p. 88), percebe-se que ela não deveria questionar o ritual, por se tratar de um "dever", um costume tradicional, instituído pela sociedade local, logo, um ethos coletivo. Mas se ela já havia rompido com parte da tradição, não lhe parecia certo permanecer ali, coberta pelo lodo e sem se manifestar. É o "ethos dito" da mãe, portanto, que rompe mais uma vez o cumprimento da tradição e "autoriza" 
Farida a interceder por sua progenitora: - "Parem, ela está sofrer" [...]. (COUTO, 1995, p. 88) $\mathrm{Na}$ perspectiva de Moreira, esta cena pode ser compreendida, ainda, da seguinte maneira:

[...] o ritual de sacrifício das mulheres [...] é inserido numa narrativa em que crenças e costumes tradicionais são utilizados para fins individuais, contrariando seu objetivo de atenderem a benefícios coletivos. O significado original da tradição, nesse caso, implica na manutenção de um determinado lugar de poder: o de evocá-la. [...] Para a mulher, a quem cabe purgar os pecados da comunidade, o ritual impõe-se como um constrangimento, como um peso de uma tradição à qual ela deve submeter-se, em amarga resignação. A encenação do ritual se apresenta como denúncia do choque entre dois mundos: um coletivo, comunitário, no qual os costumes convergiam para uma verdade do grupo: outro individual, segregador e orientador por interesses particularizadores, marcados pela ambição, pela traição, pela indiferença, pela maldade.

A partir das considerações de Moreira (2005), podemos inferir que temos o choque entre dois mundos (tradicional e moderno), entre dois tempos (passado e presente), entre dois ethé (individual e coletivo), e um status que garante poder àquelas que podem promover os rituais e, em nome da crença, selecionar, quem vive e quem morre. Isso nos remete à uma crítica acerca da manutenção de crenças, valores e tradições que, na modernidade, passam a ser questionados, convocando-se outras leis e a revisão de certos estereótipos. O ethos das mulheres que conduzem a cerimônia revela, ainda, que a própria mulher pode excluir seu próprio gênero, rompendo com um "ethos de identificação" (conforme termo de CHARAUDEAU, 2011). Logo, essa mulher responsável por unir e transmitir valores aos filhos, por meio de seu status, pode, inclusive, romper com o elo que identifica ou deveria identificar a própria mulher dentro da sociedade. Essa situação demonstra o poder e o valor dessa mulher em sua coletividade.

Como vimos, o ethos 'dito' da mãe permite ou autoriza o ethos 'dito' da filha. Farida reconhece que o ritual - chimussi - é uma forma de sofrimento, logo, mais uma forma de punir mãe e filha que já vivem reclusas - excluídas pelas próprias mulheres de sua vila natal. Esse acontecimento nos permite notar que não há que se falar em um ethos estático para o grupo de mulheres de dada sociedade, pois, como vimos, a própria tradição pode influenciar na ruptura desse ethos. Logo, determinadas tradições, a não aceitação dos costumes mais austeros e o momento vivenciado pelo grupo (guerra) são fatores condicionantes do ethos da mulher moçambicana e, portanto, do ethos da coletividade, firmando-o em aspectos positivos e agregadores ou negativos e segregadores.

Dessa maneira, é no confronto dessa mãe e filha com as demais mulheres que a identidade narrada de Farida e de sua mãe revelam sua fragilidade. As ideologias que permeiam as relações sociais na comunidade da gêmea Farida procuram, portanto, manipular essas identidades frágeis. Diante disso, inferimos que essa reconfiguração do pathos e do logos é um 
recurso de manipulação do ethos dessas personagens. Em outras palavras, essa mãe, ao romper com algo em que já não acreditava ou que não comungava mais como um valor cultural a ser seguido e também a ser transmitido para sua filha Farida, mostra-nos que o ethos individual não está imune a uma fragmentação na cadeia de eventos culturais que sustentam ou sustentavam esse povoado. O ethos, na qualidade de estrutura cultural, propõe que se abra mão do individual em prol do coletivo. Entretanto, a mãe de Farida anuncia a variedade na unidade quando não cumpre ou não concorda com o que a comunidade prega. E assim também parece acontecer com Farida. O que confirma, como vimos, que dentro de uma comunidade, o próprio ethos partilhado pode ser alterado também em função do pathos, do logos e das circunstâncias.

Como os habitantes locais não questionam a lealdade e a integridade da mãe das gêmeas quanto a cumprir todas as etapas da tradição (abrir mão da filha, não se lamentar, isolar-se da comunidade), supõe-se que ela está investida, por seu status e por seus papéis, de um ethos de honestidade, uma vez que dá o exemplo de se manter fiel ao ethos coletivo, seguindo a linha de pensamento e de ação de sua comunidade, ou seja, reafirmando o estereótipo. Ao se permitir dizer que deseja que a deixem em paz, manifestando-se contra o constrangimento que lhe é imputado, ela, na verdade, constrói um ethos de prenúncio da modernidade, o qual revela que os novos tempos exigem novos olhares e novas maneiras de lidar com as situações. Assim sendo, se ela rompe, parcialmente, com o 'ethos de identificação coletivo' (conforme termo de CHARAUDEAU, 2011), que faz com que as mães da comunidade se identifiquem umas com as outras ao agirem da mesma maneira em situação semelhante em prol da comunidade, ela sinaliza a abertura de novos posicionamentos e a possibilidade de um novo imaginário sociodiscursivo.

As atitudes dessa mãe demonstram-nos que, se a guerra desloca fisicamente as pessoas para fugirem dela, esse deslocamento atua no sentido de modificar, inclusive, o modo de pensar das pessoas e de reagir a determinadas situações diferentemente do que se espera. Como dito, o ethos da mãe de Farida não reflete, necessariamente, sua identificação real ou pressuposta pelo grupo no qual se insere, apesar de o ethos dessa coletividade procurar manter-se inalterado em relação ao cumprimento dos rituais mais severos nesse período de turbulências que afeta a todos, assim como sua cultura, sua percepção de mundo. Logo, a atitude da mãe das gêmeas (manter viva a filha) implica, de certo modo, que não é porque os membros de sua sociedade não adotam entre si um comportamento mais igualitário, que ela não possa fazê-lo. Isso remete-nos, novamente, à percepção de que o ethos é mutável e procura adaptar-se às novas condições (físicas, psicológicas, históricas, sociais...) do lugar e das pessoas desse lugar. Desse modo, o pathos e o logos também sofrem interferências externas que refletem internamente nessas pessoas, o que notamos com a mãe das gêmeas e com Farida.

Assim sendo, o ethos da mãe das gêmeas parece aludir a um possível enfraquecimento da força da tradição que está sucumbindo junto com os habitantes desse local. E esse enfraquecimento parece aludir também à necessidade da reestruturação da identificação desse povo. 
O momento histórico, marcado pela transformação, sujeita o ethos cultural às mudanças. A obra de Couto (1995) sinaliza que grupos tradicionais, vistos como hegemônicos, têm suas identidades transformadas, o que leva à uma reflexão sobre a problemática da formação da subjetividade colocando em questão o ethos coletivo.

Podemos notar, ainda, que, mesmo que essa mãe apresente um 'ethos de humanidade' (conforme termo de CHARAUDEAU, 2011) ao permitir que sua filha Carolinda não seja vitimada pela tradição local, o mesmo não se dá em relação aos demais membros de sua comunidade, já que ela permite, com seu ato, que vários problemas se instalem na vila - "A terra caiu em desordem, sopraram ventos que arderam no sol, secaram fontes e lagos. As nuvens, medrosas, fugiram. A fome e a morte instalaram residência." (COUTO, 1995, p. 87) A mãe de Farida mostra-se voltada para o que lhe restou como família, ao negar-se a seguir, cegamente, os preceitos da coletividade. E, com esse gesto, ela mostra o efeito patêmico de suas ações. Tudo isso nos leva a acreditar que o ethos pode ser construído a partir das imagens que representam discursos culturais e, também, a partir daqueles que estigmatizam pessoas (gêmeos, albinos) e comportamentos que vão de encontro ao que é permitido pelo grupo. Entretanto, nota-se também que as circunstâncias fazem o próprio indivíduo questionar a si próprio e, por conseguinte, sua cultura, seus ethé e sua identificação.

Os ethé dessa mãe, portanto, põem em xeque sua participação no grupo e, ao mesmo tempo, levam os interlocutores a questionarem o fechamento em si desse ethos coletivo e até que ponto ele deve ser respeitado e acatado em prol de uma total identificação do individual com seus semelhantes e até que ponto a abertura para o novo pode ser benéfica ou não. Assim, o gesto de poupar a filha parece assinalar a chegada de um tempo no qual as tradições mais austeras parecem não fazer mais sentido em função dos novos tempos, das novas perspectivas, dos novos horizontes a serem desenhados a partir das guerras (colonial e civil) que vão assolar Moçambique e que exigirão novo olhar sobre os modos de viver, de habitar e de se relacionar entre os membros de uma mesma comunidade e entre os outros (locais ou estrangeiros).

Há que se notar, ainda, que se o preço a se pagar pelo ato transgressor é alto para os habitantes da vila, o é também para a mãe de Farida e de Carolinda, já que ela também sofre com as calamidades que se abatem sobre a comunidade. Não devemos pensar que suas atitudes tendem a apontar a desvalorização da história de seu povo. Ao contrário disso, reafirmamos que seu ethos mostrado pretende demonstrar que a história e a memória, assim como o próprio ethos coletivo, não são estanques, pois se abrem para novos tempos, mesmo que, forçadamente, mas sem desprezar ou se desfazer completamente dos costumes locais que fazem parte dessa comunidade. Logo, não há uma cisão total dessa mãe com sua natureza, com suas tradições e seus costumes, e sim um retorno a si mesma, um autoconhecimento suscitado pelo outro, pelas novas situações (colonização, guerras, fome, seca, mortes, entre outros) que lhe permitem novos olhares, outras escolhas em virtude dos acontecimentos e, portanto, outra identificação, outros ethé. 


\section{CoNSIDERAÇõEs FINAIS}

Os caminhos percorridos para que este artigo fosse realizado nos levam a inferir a importância do ethos para a Análise do Discurso, inclusive, na apreciação crítica do discurso literário - especificamente, na reconstituição dos ethé da personagem selecionada para este estudo e a percepção dela sobre os imaginários sociodiscursivos de sua região e que refletem alguns dos imaginários sociodiscursivos de Moçambique. Nesta análise, ao enfocar as provas retóricas (ethos, pathos e logos), lançamos nosso olhar, principalmente, sobre um desses componentes, o ethos, a partir dos estudos de Maingueneau, a fim de compreender como ele, o ethos, pode ser trabalhado também no discurso literário, gênero textual que mobiliza subjetividades e, como vimos na narrativa de Couto (1995), carrega representações dos ethé de Moçambique. Daí a necessidade de entender o discurso literário, pelo viés da $\mathrm{AD}$, como um discurso que nos permite estudar suas especificidades discursivas, buscando contribuir para a compreensão dessa noção discursiva - o ethos - como ferramenta para a análise do discurso literário.

Por fim, resta-nos dizer que, na literatura coutiana, é possível notar que história e ficção fundem-se, inclusive, a partir do diálogo com expressões que pertencem à oralidade, que a aproxima da tradição de contar histórias, de rituais, de relatos e de mitos que se misturam para construir processos de negociação de sentidos e, portanto, de construções dos ethé ('pré-discursivo', 'discursivo mostrado' e 'discursivo dito') e de identificações para as personagens do romance.

\section{REFERÊNCIAS}

AMOSSY, R. Introdução - Da noção retórica de ethos à análise do discurso. O ethos na intersecção das disciplinas: retórica, pragmática, sociologia dos campos. In: AMOSSY, R. (Org.). Imagens de si no discurso: a construção do ethos. São Paulo: Contexto, 2005, p. 9-28; p. 119-144.

ARISTÓTELES. [384-322 a.C.]. Retórica. Lisboa: Imprensa Nacional - Casa da Moeda, 1998.

BOURDIEU, P. Le sens pratique. Paris: Minuit, 1980.

CHARAUDEAU, P. O ethos, uma estratégia do discurso político. Da ideologia aos imaginários sociodiscursivos. In: CHARAUDEAU, P. Discurso político. 2. ed. Trad. Fabiana Komesu e Dilson Ferreira da Cruz. São Paulo: Contexto, 2011, p. 113-166; p. 187-208.

CHEVALIER, J.; GHEERBRANT, A. Dicionário de símbolos, mitos, sonhos, costumes, gestos, formas, figuras, cores, números. Rio de Janeiro: José Olympio, 1991, p. 197.

COUTO, M. Terra sonâmbula. Rio de Janeiro: Nova Fronteira, 1995. 
HALL, S. A identidade cultural na pós-modernidade. $3^{\mathrm{a}}$ ed. Trad. Tomaz Tadeu da Silva, Guaciara Lopes Louro. Rio de Janeiro: DP\&A, 1999.

JUNOD, H. A. Cantos e contos dos Bantos I e II. Lourenço Marques: Imprensa Nacional de Moçambique, 1974.

LEITE, A. M. Literaturas Africanas e Formulações Pós-Coloniais. Lisboa: Edições Colibri, 2013.

MAINGUENEAU, D. O ethos. In: MAINGUENEAU, D. Análise de textos de comunicação. 6. ed. Tradução de Cecília P. de Sousa-e-Silva e Décio Rocha. São Paulo: Cortez, 2011, p. 95-103.

MAINGUENEAU, D. Problemas de ethos. In: POSSENTI, S.; SOUZA-E-SILVA, Maria Cecília Pérez de. (Orgs.). Cenas da Enunciação. Trad. Sírio Possenti. São Paulo: Parábola, 2008a, p. 55-73.

MAINGUENEAU, D. A propósito do ethos. In: MOTTA, A. R.; SALGADO, L. (Orgs.). Ethos Discursivo. São Paulo: Contexto, 2008b, p. 11-29.

MAINGUENEAU, D. O ethos. In: MAINGUENEAU, D. Discurso literário. Tradução de Adail Sobral. São Paulo: Contexto, 2006, p. 266-290.

MAINGUENEAU, D. Ethos, cenografia, incorporação. In: AMOSSY, R. (Org.). A imagem de si no discurso: a construção do ethos. São Paulo: Contexto, 2005, p. 69-92.

MAINGUENEAU, D. O etos. In: MAINGUENEAU, D. O contexto da obra literária: enunciação, escritor, sociedade. 2. ed. Tradução de Marina Appenzzeler. Revisão da Tradução Eduardo Brandão. São Paulo: Martins Fontes, 2001, p. 137-154.

MOREIRA, T. T. O vão da voz: a metamorfose do narrador na ficção. Belo Horizonte: Editora PUC Minas, Edições Horta Grande Ltda., 2005.

Recebido para publicação em: 22 out. 2020. Aceito para publicação em: 25 out. 2021. 